\title{
Effect of Pulses Distribution in a Buck Converter Controlled with Pulse Skipping Modulation
}

\author{
Lorenzo Ciani \\ Dip. di Ing. dell'Informazione \\ Università di Firenze \\ Firenze, Italy \\ lorenzo.ciani@unifi.it
}

\author{
Giulia Guidi \\ Dip. di Ing. dell'Informazione \\ Università di Firenze \\ Firenze, Italy \\ giulia.guidi@unifi.it
}

\author{
Marcantonio Catelani \\ Dip. di Ing. dell'Informazione \\ Università di Firenze \\ Firenze, Italy \\ marcantonio.catelani@unifi.it
}

\author{
Alessandro Bartolini \\ Dip. di Ing. dell'Informazione \\ Università di Firenze \\ Firenze, Italy \\ a.bartolini@unifi.it
}

\author{
Fabio Corti \\ Dip. di Ingegneria Industriale \\ Università di Perugia \\ Perugia, Italy \\ fabio.corti@unipg.it
}

\author{
Alberto Reatti \\ Dip. di Ing. dell'Informazione \\ Università di Firenze \\ Firenze, Italy \\ alberto.reatti@unifi.it
}

\begin{abstract}
Nowadays, Wireless Sensor Networks are more and more applied in different fields. Generally, sensor nodes used in wireless sensor networks are powered by batteries and photovoltaic panels. Consequently, the design of an efficient DCDC converter represents a critical aspect in order to ensure high efficiency and minimize losses. Moreover, it is fundamental to design a DC-DC converter able to ensure high efficiency also in case of light load. Trying to solve these needs, this paper evaluates the advantages of the Pulse Skipping Modulation (PSM) in a prototype of a Buck converter. Different pulses distributions are compared and analyzed. A comparison in terms of output voltage ripple and DC-DC conversion efficiency is presented and discussed. The output voltage waveforms in four different scenarios at different operating condition are shown. The experimental results are obtained through a developed printed circuit board driven by an ESP 32 microcontroller and a suitable algorithm.
\end{abstract}

Keywords - Buck Converter, Pulse Skipping Modulation, Wireless Sensor Networks, Conversion Efficiency.

\section{INTRODUCTION}

The continuous development of innovative DC-DC power converter allows to precisely regulate current and voltage achieving high conversion efficiency. However, most applications require particular operating conditions not suitable to ensure high conversion efficiency [1]-[5]. In practice, the DCDC conversion efficiency is primarily affected by the load. As a matter of fact, most converters decrease their efficiency in presence of light load.

Both hardware and software play a fundamental role in order to ensure high efficiency over wide load variation, as well as to guarantee high system reliability [6]-[10].

During the design of a DC-DC converter with this kind of requirements particular attention must be place on two different aspects:

- The selection of the proper optimal components value [9].

- The power switching devices modulation [12].
The Pulse Width Modulation (PWM) represents the most used modulation technique for DC-DC converter. Despite this, PWM operates at a fixed frequency, and consequently it leads to high switching losses in presence of light load. Pulse Skipping Modulation (PSM) represents an optimal solution to increase the DC-DC conversion efficiency at light load. PSM is based on a constant pulse width and a constant switching frequency, while the output voltage is regulated skipping some cycle of the modulation. In case light load condition represents an operating state relevant in the operating life of a DC-DC converter, then the use of PSM is particularly suitable to achieve high efficiency performances. Flexibility of PSM has been proved in many works in literature dealing with different applications. In [13], the PSM is used in an LLC resonant converter for electric vehicle charging. The PSM is used to control the converter, achieve the zero-voltage switching condition and reduce EMI emission. In [14], the PSM is used to control a Buck-Boost converter for energy harvesting in an Internet of Things (IoT) low-power sensor. In [15], the PSM is used to control a semibridgeless rectifier of an inductive wireless power transfer system. Soft switching condition and continuous output voltage have been achieved using PSM.

DC-DC converter plays a fundamental role also in Wireless Sensor Networks (WSNs). A WSN is a wireless networks used to monitor physical or environmental conditions and to cooperatively pass their data though the network to a main location or sink where the data can be observed and analysed. WSNs are rapidly spreading worldwide to monitor different phenomena in several industrial and technological fields [16][17]. Generally, the nodes of a WSN installed outdoor are powered using batteries and/or photovoltaic panels. Then, they require to guarantee high DC-DC conversion efficiency in light load conditions.

In this paper, starting from a previous work [15], the benefits deriving from the use of PSM in a Buck converter used to regulate the energy in a node of a WSN are evaluated. The node presented in [15] harvest energy from a photovoltaic panel and charge a battery to guarantee autonomy. Even if the modelling of the photovoltaic source represents one of the key aspects for the correct sizing of the converter [18]-[20], in this paper it is 
assumed that the buck is powered by a voltage generator. Some guidelines for a correct implementation of PSM are derived.

The paper is organized as follows. In Section II the PSM is briefly introduced. In Section III the developed PCB Buck converter is described. In Section IV, the experimental results and the measured waveforms are shown. Finally, in Section V, the results are summarized in the conclusion section.

\section{PULSE SKIPPING MODULATION}

The electric circuit of the Buck converter under analysis is shown in the electrical schematic in Fig. 1. A synchronous topology has been selected since it avoids the conduction losses on the diode due to the forward voltage with consequent increment of conversion efficiency [15].

As shown in Fig. 2, the PSM is characterised by two different periods. The high frequency period $T$ (also known as inner period) and the outer period (low-frequency) related with the number of pulses $T_{s}=N T$. The duty cycle is assumed to be constant to $D=0.5$.

The core of the Pulse Skipping Modulation consists on skip some pulse of the high frequency inner period. Thus, $p$ stands for the number of periods with pulses, while $q$ represents the number of skipped periods. Consequently, the relation between the inner and outer period is:

$$
T_{S}=(p+q) \cdot T
$$

As shown in [15] and [18], the voltage transfer function of a Buck converter operating with PSM is proportional to the converter duty cycle $D$ as follow:

$$
\frac{V_{o}}{V_{i}}=(1-M) \cdot D
$$

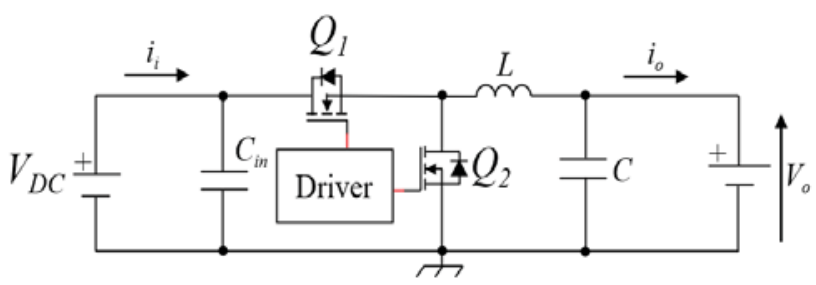

Fig. 1. Topology of the Buck converter under analysis.

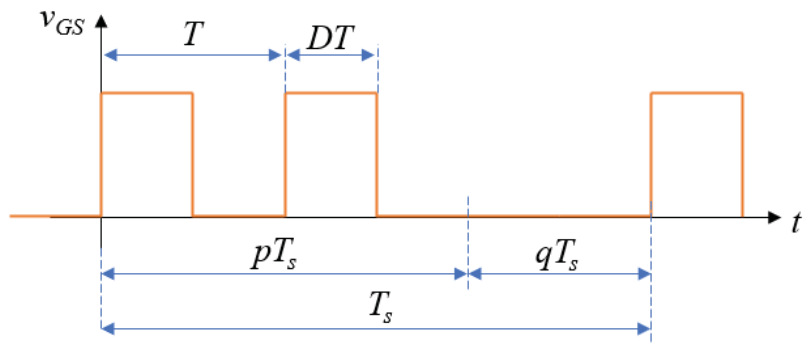

Fig. 2. Pulse skipping modulation. Represented case: $N=3, p=2, q=1$.
Where $M$ is given by:

$$
M=\frac{q}{(p+q)}
$$

One of the most important aspects of PSM implementation is the distribution of the pulses over the outer period $T_{s}$. The pulses distribution highly affects the performance of the converter in terms of inductor current ripple and output voltage ripple.

In this paper, two different distributions are compared. In the first one all the pulses $\mathrm{p}$ are distributed at the beginning of the periods Ts (blue trace in Fig. 3). While in the second distribution the pulses $\mathrm{p}$ are evenly distributed in the period Ts (see red trend shown in Fig. 3).

Fig.4 shows the algorithm implemented on the control circuit, used to generate the distribution map, which depends on the number of pulses.

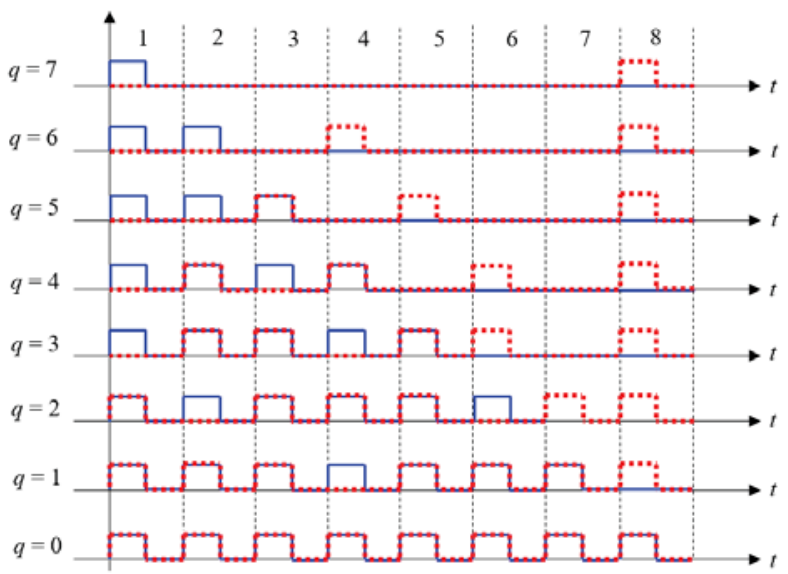

Fig. 3. Comparison between two different distribution pulses in a PSM. The blue trace and the red trace are referred as "strategy 1" and "strategy 2" respectively.

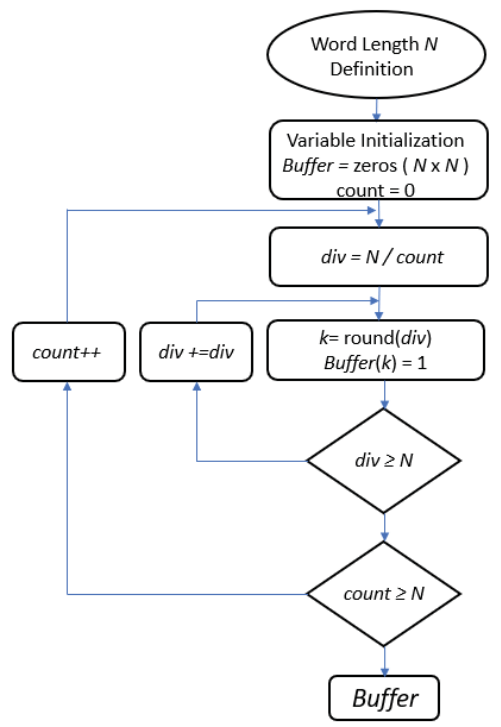

Fig. 4. Algorithm used to generate the map with uniform distribution of pulses over the long periods $T_{s}$. 
The first step of the algorithm is the definition of $N$, which represents the maximum number of pulses inside the outer period. Hence, for each "count" (1 to $N$ ) of skipped pulses number in a specific distribution, the algorithm removes a pulse after a rounded integer number of pulses obtained through iterative divisions. Thus, the skipped pulses are evenly distributed uniformly in the outer period.

\section{DESIGNED PROTOTYPE}

To test and compare the effects that the pulses distribution has on the efficiency and on output voltage ripple, a PCB (Printed Circuit Board) prototype Buck converter has been properly designed using the procedures shown in [11] and [21][24].

In Fig. 5, the developed PCB board is shown. An ESP32 microcontroller by Espressif has been used to change the duty cycle of the PWM modulation or the number of pulses of the PSM modulation.

The main components mounted in the prototype buck converter under test are summarized in Table I highlighting the manufacturer part number and the measured value.

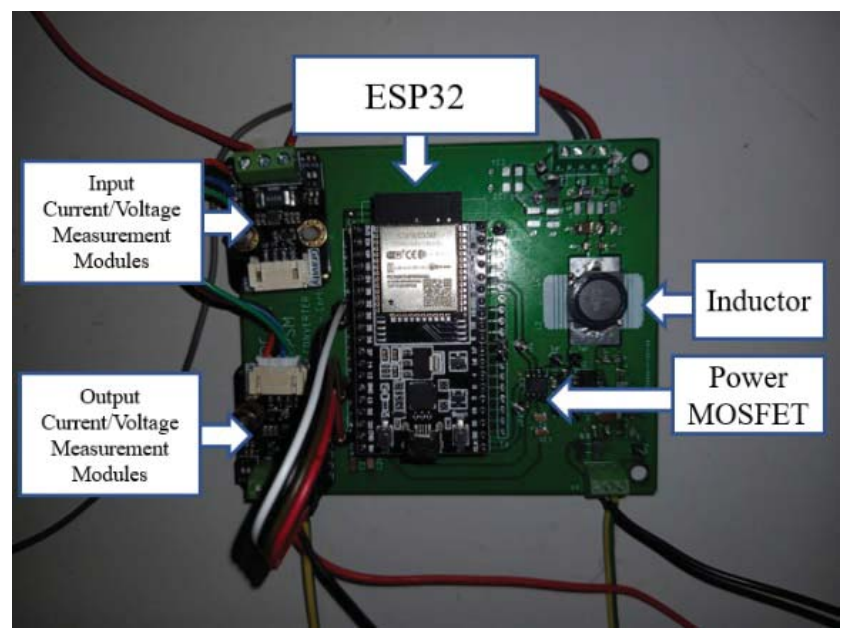

Fig. 5. Developed PCB prototype highlighting the inductor L, the switching MOSFET, the ESP32 microcotntroller and the input and output modules used to measure both current and voltage.

TABLE I. BUCK CONVERTER MAIN COMPONENTS

\begin{tabular}{|l|l|l|}
\hline Component & $\begin{array}{l}\text { Manufacturer Part } \\
\text { Number }\end{array}$ & $\begin{array}{l}\text { Measured } \\
\text { Value }\end{array}$ \\
\hline Inductor $L$ & NS12575T470MN & $L=46.3 \mu \mathrm{H}$ \\
\hline Output Capacitor $C$ & GRM32ER7YA106KA & $C=9.84 \mu \mathrm{F}$ \\
\hline MOSFETs $Q_{1}, Q_{2}$ & BSO150N03 & $r_{D S}=18.2 \mathrm{~m} \Omega$ \\
\hline
\end{tabular}

\section{EXPERIMENTAL RESULTS}

For the sake of comparison, four different case studies have been presented and compared in Table II.

To compare the effects of the pulses distribution on the output voltage ripple, the experimental setup shown in Fig. 6 has been realized. A DC power supply has been used to generate the input voltage instead of a photovoltaic panel.

Two $1.5 \mathrm{~m} \Omega$ series resistances have been used to simulate the light load of a sensor node for Wireless Sensor Network applications. One oscilloscope and two multimeters have been used to measure the electrical parameters of the converter.

The signals acquired using the oscilloscope are illustrated in Fig. 7 in case of the first pulse distribution ("strategy 1") using multiple pulses located at the beginning of the outer period. Each image represents a different operating condition as in TABLE II. Quite the same, Fig. 8 shows the characterization of the prototype when the second pulse distribution ("strategy 2) is considered. In this case, the pulses are evenly distributed in the outer period. Also in this case the four different operating conditions have been presented.

The measurement results are summarized in Table III. The average value of the output voltage is not significantly affected by the pulse distribution, especially in conditions B, C and D. On the other hand, using the "Strategy 2" with pulses evenly distributed over the period, the output voltage ripple is significantly reduced.

TABLE II. OPERATING CONDITIONS

\begin{tabular}{|c|c|}
\hline Case Study & Operating Condition \\
\hline A & $V_{i}=8 \mathrm{~V}, f=1 \mathrm{MHz}, R_{L}=3.23 \Omega, p=8$ \\
\hline B & $V_{i}=8 \mathrm{~V}, f=1 \mathrm{MHz}, R_{L}=3.23 \Omega, p=16$ \\
\hline $\mathrm{C}$ & $V_{i}=8 \mathrm{~V}, f=1 \mathrm{MHz}, R_{L}=3.23 \Omega, p=24$ \\
\hline $\mathrm{D}$ & $V_{i}=8 \mathrm{~V}, f=1 \mathrm{MHz}, R_{L}=3.23 \Omega, p=32$ \\
\hline
\end{tabular}

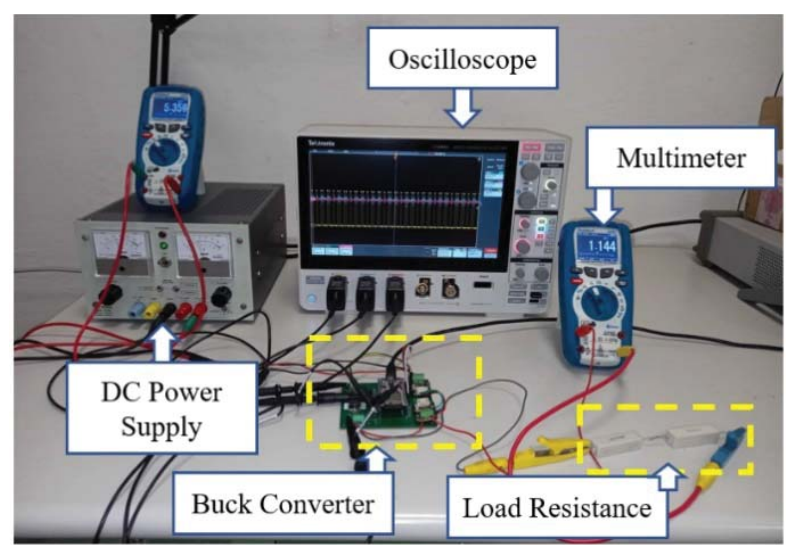

Fig. 6. Experimental setup used to test and validate the performances of the prototype. 


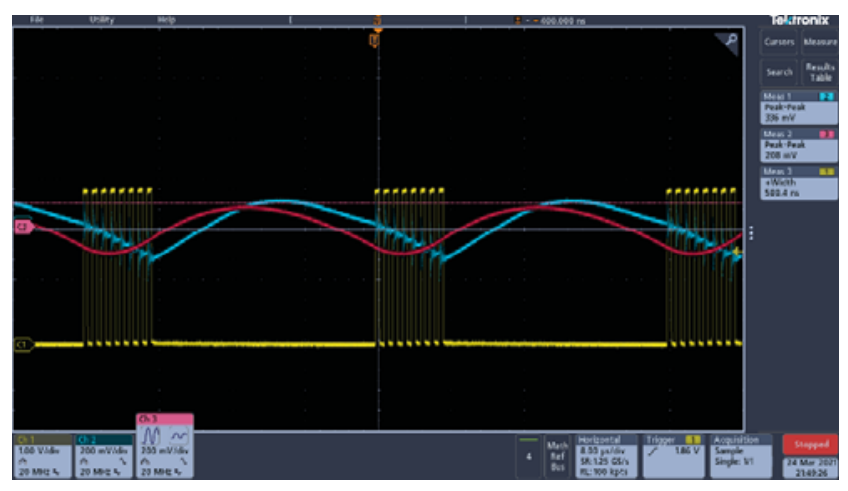

(a)

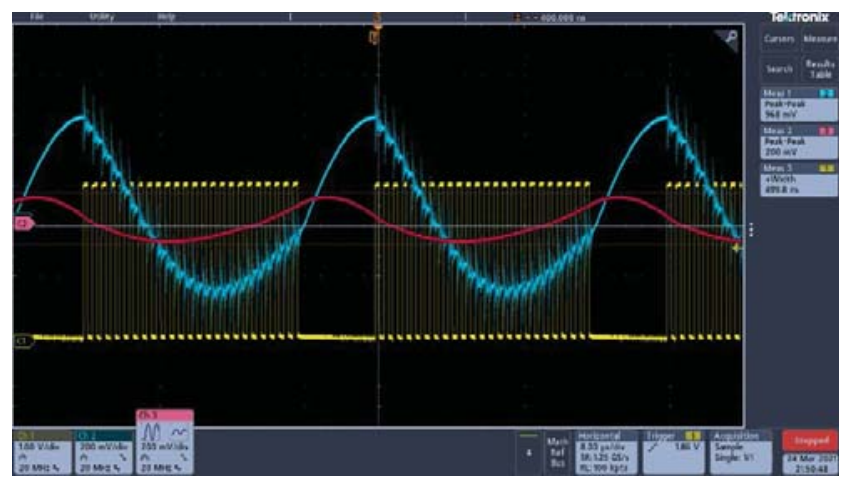

(b)

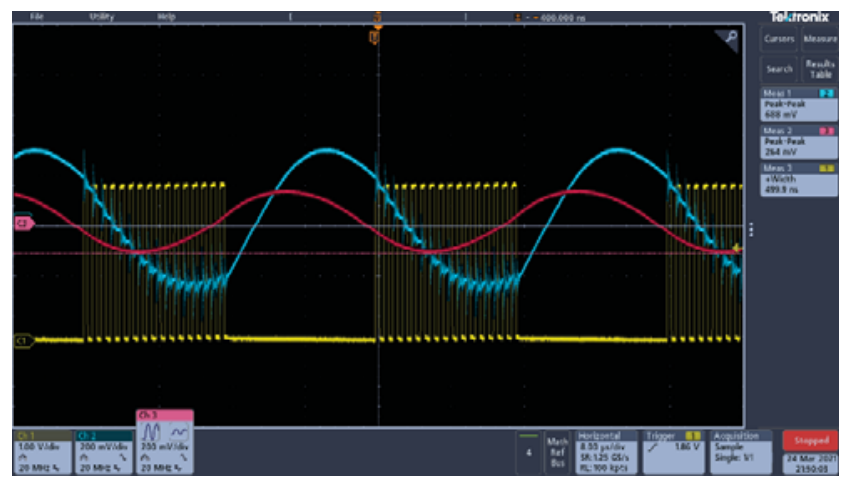

(c)

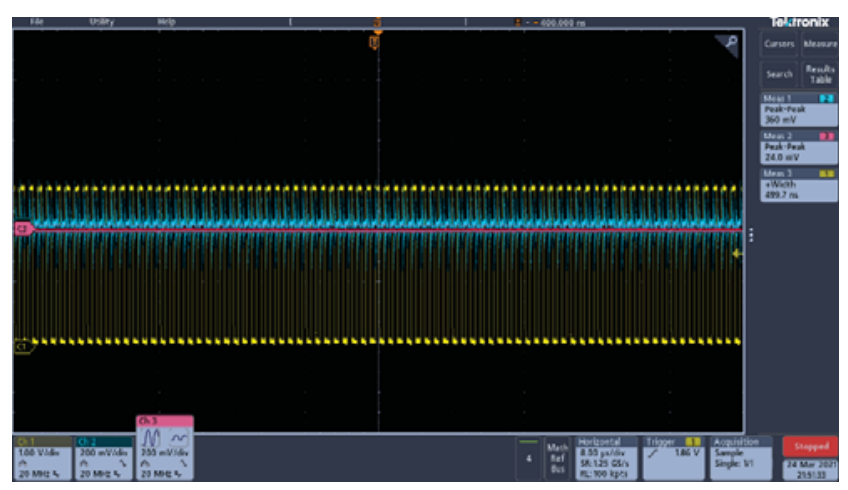

(d)

Fig. 7. Oscilloscope measurements using the first pulse distribution "strategy 1 ". The yellow trace is the upper MOSFET gate-to-source voltage $v_{G S Q} Q 1$. The blue trace is the AC coupling of the input voltage Vi. The red trace is the AC coupling of the output voltage Vo. (a) Operating condition A. (b) Operating condition B. (c) Operating condition C. (d) Operating condition D.

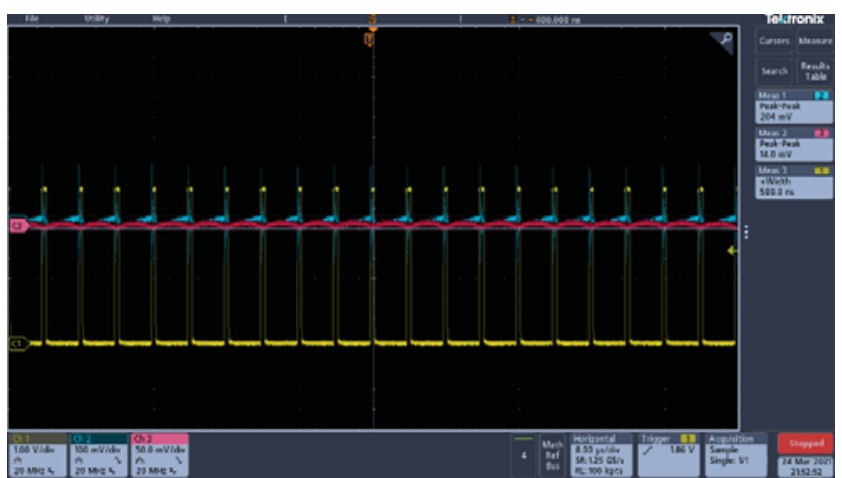

(a)

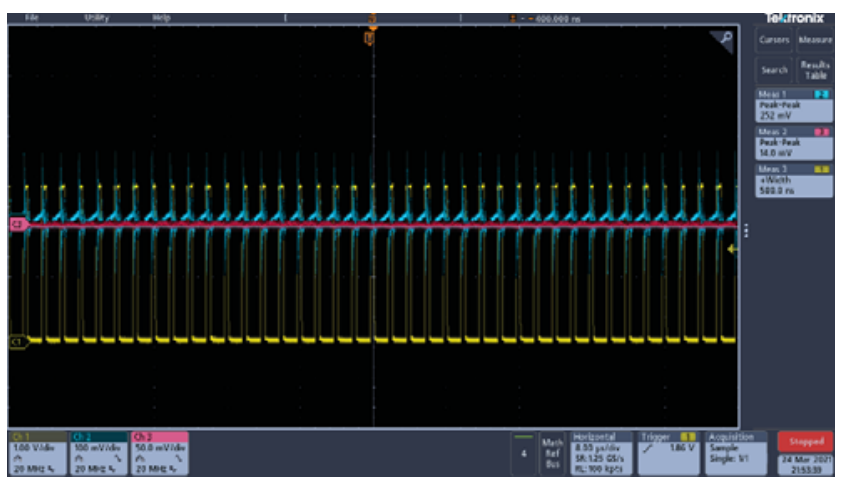

(b)

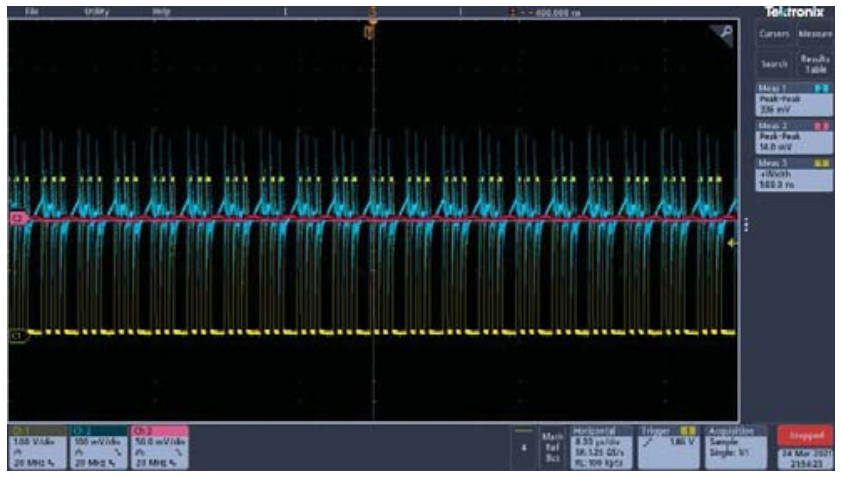

(c)

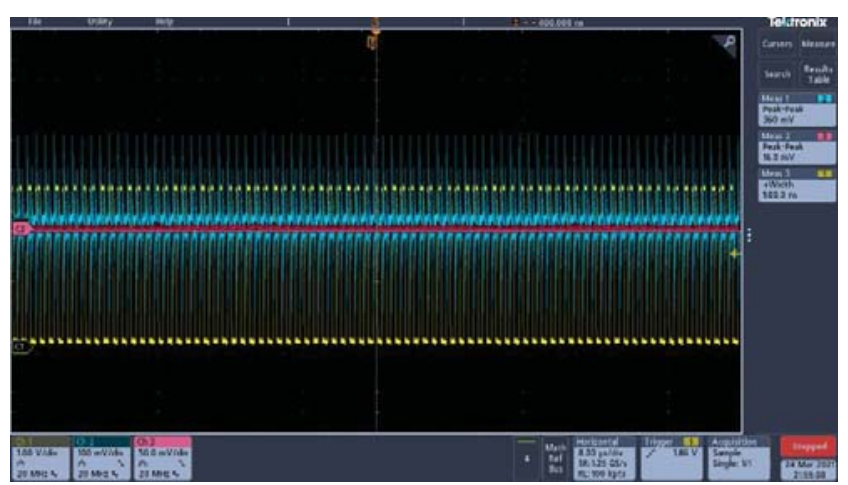

(d)

Fig. 8. Oscilloscope measurements using the pulse distribution "strategy 2". The yellow trace is the upper MOSFET gate-to-source voltage $v_{G S \_1}$. The blue trace is the AC coupling of the input voltage Vi. The red trace is the AC coupling of the output voltage Vo. (a) Operating condition A. (b) Operating condition B. (c) Operating condition C. (d) Operating condition D. 
In Fig. 9, the measured output power for different pulses using the two above-mentioned pulse distribution are shown. Similarly to the output voltage, also the output power is not remarkably affected by the different pulse distribution and the measured values are approximately the same for both the distributions.

TABLE III. Output Voltage AND Ripple For Each CASE Study

\begin{tabular}{|c|c|c|c|c|}
\hline $\begin{array}{c}\text { Case } \\
\text { Study }\end{array}$ & \multicolumn{2}{|c|}{$\begin{array}{c}\text { Average Output Voltage } \\
\boldsymbol{V}_{\boldsymbol{o}}\end{array}$} & \multicolumn{2}{c|}{$\begin{array}{c}\text { Ripple } \\
\boldsymbol{\Delta} \boldsymbol{V}_{\boldsymbol{o}}\end{array}$} \\
\hline & Strategy 1 & Strategy 2 & Strategy 1 & Strategy 2 \\
\hline$A$ & $0.98 \mathrm{~V}$ & $1.02 \mathrm{~V}$ & $336 \mathrm{mV}$ & $204 \mathrm{mV}$ \\
\hline$B$ & $1.97 \mathrm{~V}$ & $1.95 \mathrm{~V}$ & $688 \mathrm{mV}$ & $252 \mathrm{mV}$ \\
\hline$C$ & $2.94 \mathrm{~V}$ & $2.92 \mathrm{~V}$ & $968 \mathrm{mV}$ & $336 \mathrm{mV}$ \\
\hline$D$ & $3.88 \mathrm{~V}$ & $3.88 \mathrm{~V}$ & $360 \mathrm{mV}$ & $360 \mathrm{mV}$ \\
\hline
\end{tabular}

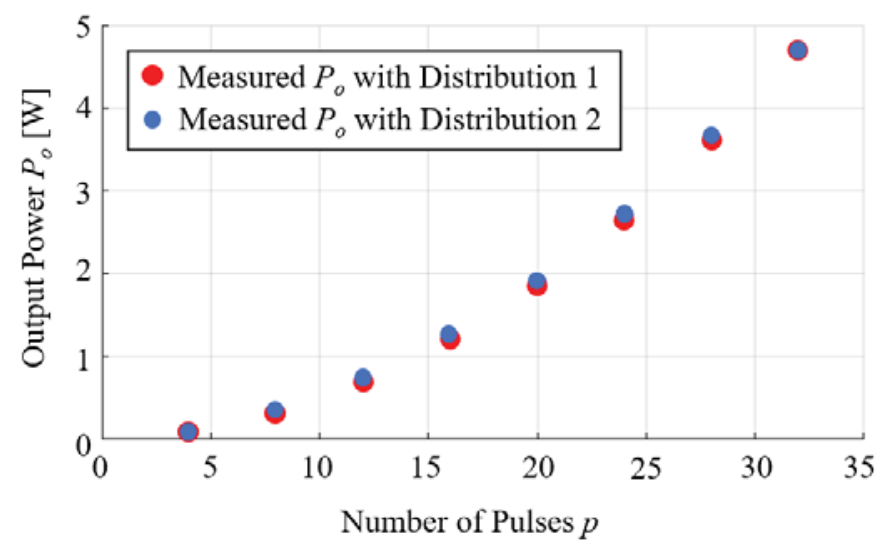

Fig. 9. Comparison of Buck converter output power using different pulse distribution strategies.

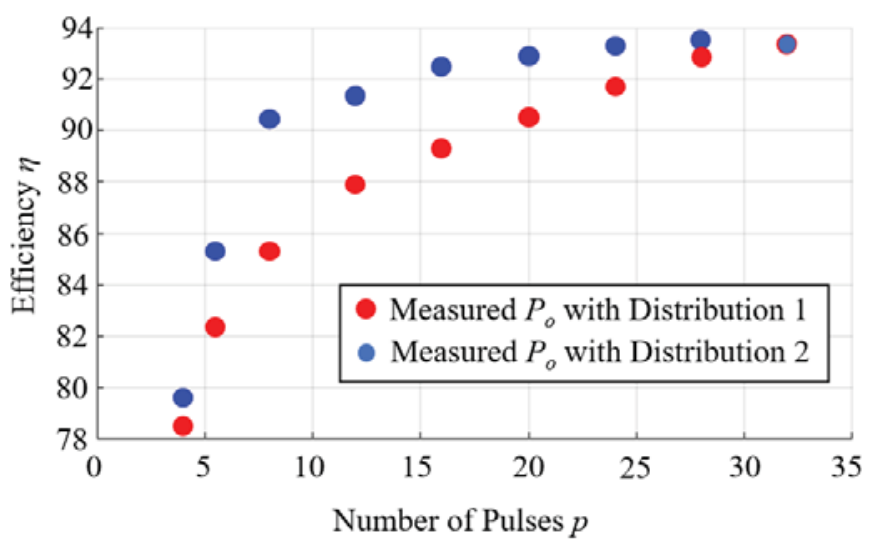

Fig. 10. Comparison of DC-DC conversion efficiency for different pulse distribution strategies.
Quite differently, the implementation of "Strategy 2" with evenly distributed pulses allows to achieve better performances in terms of efficiency. As it is possible to see in Fig.10, the DCDC conversion efficiency is remarkably improved using this strategy. The figure highlights how a uniform distribution of pulses over the period $T_{s}$ allows to achieve a significant increment of efficiency, particularly when a low number of pulses is used.

\section{CONCLUSIONS}

In this paper the output voltage ripple, output power and DCDC conversion efficiency of a Buck converter controlled with Pulse Skipping Modulation have been analysed. A comparison between two different pulses distribution has been investigated. In the first distribution the pulses are placed at the beginning of the long period Ts, while the second one is based on a pulse distribution equally spaced along the outer period Ts. The obtained experimental results show that a uniform distribution of pulses along the period Ts allows to reduce the output voltage ripple and increase the DC-DC conversion efficiency maintaining unchanged the average output voltage and the output power. These results could provide extremely useful information during the design of such kind of converter, especially for Wireless Sensor Network applications which use battery and photovoltaic panel as power source.

\section{REFERENCES}

[1] S. Zhang, T. Uematsu, K. Iokibe and Y. Toyota, "Two-port Noise Source Equivalent Circuit Model for DC/DC Buck Converter with Consideration of Load Effect," 2020 International Symposium on Electromagnetic Compatibility - EMC EUROPE, Rome, Italy, 2020, pp. 1-4, doi: 10.1109/EMCEUROPE48519.2020.9245680.

[2] Y. -W. Huang, T. -Y. Yu and T. -H. Kuo, "Transient Output-Current Regulator With Background Calibration Applied to a Buck Converter for Fast Load-Transient Response," in IEEE Solid-State Circuits Letters, vol. 3, pp. 462-465, 2020, doi: 10.1109/LSSC.2020.3026548.

[3] F. Leccese and D. G. Nottiani, "A simple method for calculating lumped parameters of planar spiral coil for wireless energy transfer," in 2012 11th International Conference on Environment and Electrical Engineering, 2012.

[4] M. Catelani and L. Ciani, "Experimental tests and reliability assessment of electronic ballast system," Microelectron. Reliab., vol. 52, no. 9-10, pp. 1833-1836, Sep. 2012.

[5] Giulio D'Emilia, Antonella Gaspari, Measurement uncertainty as an innovative management tool in modern engineering systems, IMEKO TC10 Conference, Milan, Italy, 27-28 June 2016, 197-202

[6] K. -Y. Hu, C. -H. Tsai and C. -W. Tsai, "Digital V2 Constant ONTime Control Buck Converter With Adaptive Voltage Positioning and Automatic Calibration Mechanism," in IEEE Transactions on Power Electronics, vol. 36, no. 6, pp. 7178-7188, June 2021, doi: 10.1109/TPEL.2020.3039061

[7] M. Catelani, L. Ciani, and M. Venzi, "Sensitivity analysis with MC simulation for the failure rate evaluation and reliability assessment," Measurement, vol. 74, pp. 150-158, Oct. 2015.

[8] M. Catelani, L. Ciani, V. Luongo, and R. Singuaroli, "Evaluation of the Safe Failure Fraction for an electromechanical complex system: remarks about the standard IEC61508," in 2010 IEEE Instrumentation \& Measurement Technology Conference Proceedings, 2010, pp. 949-953.

[9] F. Corti et al., "A Low-Cost Secondary-Side Controlled Electric Vehicle Wireless Charging System using a Full-Active Rectifier," 2018 
International Conference of Electrical and Electronic Technologies for Automotive, 2018, pp. 1-6, doi: 10.23919/EETA.2018.8493165.

[10] E. Locorotondo, L. Pugi, F. Corti, L. Becchi and F. Grasso, "Analytical Model of Power MOSFET Switching Losses due to Parasitic Components," 2019 IEEE 5th International forum on Research and Technology for Society and Industry (RTSI), 2019, pp. 331-336, doi: 10.1109/RTSI.2019.8895562.

[11] F. Corti, A. Reatti, G. Patrizi, L. Ciani, M. Catelani, "Probabilistic evaluation of power converters as support in their design", IET Power Electronics, Volume 13, Issue 19, 30 December 2020, Pages 4542-4550.

[12] Y. Wang, P. Li and S. Lai, "Robust and Efficient Transistor-Level Envelope-Following Analysis of PWM/PFM/PSM DC-DC Converters," in IEEE Transactions on Computer-Aided Design of Integrated Circuits and Systems, vol. 35, no. 11, pp. 1836-1847, Nov. 2016, doi: 10.1109/TCAD.2016.2524565.

[13] C. Suthar, J. B. Sangiri, S. Maiti and C. Chakraborty, "A Pulse density modulated LLC resonant converter based battery charger for HEV/PHEV application," 2019 IEEE International Conference on Electrical, Computer and Communication Technologies (ICECCT), Coimbatore, India, 2019, pp. 1-7, doi: 10.1109/ICECCT.2019.8869189.

[14] S. Nguyen, K. Yuk and R. Amirtharajah, "Pulse skipping modulation method for multiple input buck boost converter," 2018 IEEE 19th Wireless and Microwave Technology Conference (WAMICON), Sand Key, FL, USA, 2018, pp. 1-4, doi: 10.1109/WAMICON.2018.8363919.

[15] J. H. Lee, W. Son, S. Ann, J. Byun and B. K. Lee, "Improved Pulse Density Modulation with a Distribution Algorithm for Semi-Bridgeless Rectifier of Inductive Power Transfer System in Electric Vehicles," 2019 10th International Conference on Power Electronics and ECCE Asia (ICPE 2019 - ECCE Asia), Busan, Korea (South), 2019, pp. 1-6.

[16] M. Carratù, M. Ferro, A. Pietrosanto, and P. Sommella, "Wireless Sensor Network for Low-cost Air Quality Measurement," J. Phys. Conf. Ser., vol. 1065, p. 192004, Aug. 2018.

[17] M. Carratu, M. Ferro, A. Pietrosanto, P. Sommella, and V. Paciello, "A Smart Wireless Sensor Network For PM10 Measurement," in 2019 IEEE International Symposium on Measurements \& Networking (M\&N), 2019, pp. 1-6.
[18] A. Bartolini, F. Corti, A. Reatti, L. Ciani, F. Grasso and M. K. Kazimierczuk, "Analysis and Design of Stand-Alone Photovoltaic System for precision agriculture network of sensors," 2020 IEEE International Conference on Environment and Electrical Engineering and 2020 IEEE Industrial and Commercial Power Systems Europe (EEEIC / I\&CPS Europe), Madrid, Spain, 2020, pp. 1-5, doi: 10.1109/EEEIC/ICPSEurope49358.2020.9160554.

[19] F. Corti, A. Laudani, G.M. Lozito, A. Reatti, “Computationally efficient modeling of DC-DC converters for PV applications", Energies, Vol. 13, Issue 19, October 2020, Article number 5100.

[20] O. Boutebba, A. Laudani, G. M. Lozito, F. Corti, A. Reatti and S. Semcheddine, "A Neural Adaptive Assisted Backstepping Controller for MPPT in Photovoltaic Applications," 2020 IEEE International Conference on Environment and Electrical Engineering and 2020 IEEE Industrial and Commercial Power Systems Europe (EEEIC / I\&CPS Europe), Madrid, Spain, 2020, pp. 1-6, doi: 10.1109/EEEIC/ICPSEurope49358.2020.9160518.

[21] O. Boutebba, S. Semcheddine, F. Krim, F. Corti, A. Reatti and F. Grasso, "A Nonlinear Back-stepping Controller of DC-DC Non Inverting BuckBoost Converter for Maximizing Photovoltaic Power Extraction," 2020 IEEE International Conference on Environment and Electrical Engineering and 2020 IEEE Industrial and Commercial Power Systems Europe (EEEIC / I\&CPS Europe), Madrid, Spain, 2020, pp. 1-6, doi: 10.1109/EEEIC/ICPSEurope49358.2020.9160634

[22] L. Ping, Z. Bo, W. Shun Ping, F. Yong, "Modeling and Analysis of Pulse Skip Modulation*", Journal of Electronics SCience and Technology of China, Mar. 2006, Vol.4 No.1.

[23] Ping Luo, Luyang Luo, Zhaoji Li, Jian Yang and Guangiv Chen, "Skip cycle modulation in switching DC-DC converter," IEEE 2002 International Conference on Communications, Circuits and Systems and West Sino Expositions, Chengdu, China, 2002, pp. 1716-1719 vol.2, doi: 10.1109/ICCCAS.2002.1179107.

[24] F. Corti, A. Reatti, E. Cardelli, A. Faba and H. P. Rimal, "Improved Spice Simulation of Dynamic Core Losses for Ferrites with Non-Uniform Field and its Experimental Validation," in IEEE Transactions on Industrial Electronics, doi: 10.1109/TIE.2020.3044783. 